\title{
Intervenção fonoaudiológica em recém-nascido pré-termo com gastrosquise
}

\section{Speech language therapy in a preterm newborn infant with gastroschisis}

\author{
Marilene de Souza Rocha ${ }^{1}$, Susana Elena Delgado ${ }^{2}$
}

\begin{abstract}
RESUMO
O objetivo deste estudo foi descrever a intervenção fonoaudiológica para a adequação da função alimentar por meio da avaliação e tratamento do sistema estomatognático e suas funções. O estudo foi feito a partir do relato de caso de um recém-nascido prétermo com gastrosquise que foi alimentado por sonda, atendido na Neonatologia do Hospital Luterano, no período de 29/03/2005 a 22/04/2005. A avaliação fonoaudiológica foi realizada, seguindo o protocolo padronizado do serviço de Neonatologia e apresentou os seguintes resultados: órgãos do sistema estomatognático no que se refere à postura, conformação e mobilidade dentro da normalidade; reflexos orais presentes; força e ritmo adequados na sucção não nutritiva; alteração na sensibilidade oral com reflexo nauseoso anteriorizado e exacerbado; sinal de estresse de alteração respiratória durante a sucção nutritiva na mamadeira; e dificuldade de pegar o seio materno. Foram realizadas três sessões de intervenção fonoaudiológica, uma vez por semana, com orientação para a equipe de enfermagem dar continuidade na estimulação oral nos demais dias. Em uma das sessões, a mãe recebeu orientações sobre os benefícios da amamentação e a importância do uso adequado de chupetas e bico de mamadeira do tipo ortodôntico para o desenvolvimento adequado das funções orais. O recém-nascido do relato de caso teve alta sem alterações orais, mamando no seio materno com complementação de mamadeira, sugerindo desta forma, a importância da intervenção fonoaudiológica para a adequação da função alimentar.
\end{abstract}

DESCRITORES: Prematuro; Gastrosquise; Amamentação; Comportamento alimentar; Sistema estomatognático

\section{INTRODUÇÃO}

A alimentação por via oral é de extrema importância para o desenvolvimento normal do sistema estomatognático. $\mathrm{O}$ aleitamento materno, além de ser melhor tanto para o bebê quanto para a mãe, propicia um desenvolvimento mais adequado das estruturas neuromotoras necessárias à função alimentar ${ }^{(1)}$.

Embora se saiba que a alimentação por via oral é a mais adequada para o perfeito desenvolvimento das estruturas sensório motoras, muitas vezes existem situações em que, para garantir a sobrevivência de recém-nascido pré-termo (RNPT) extremos e patológicos, se faz necessária utilização de alimentação parenteral, enteral e/ou gavagem. A nutrição

(1) Especializanda em Motricidade Oral pela Universidade Luterana do Brasil - ULBRA - Canoas (RS), Brasil.

(2) Mestre em Saúde Coletiva; Professora Adjunto do Curso de Fonoaudiologia da Universidade Luterana do Brasil - ULBRA - Canoas (RS), Brasil. Trabalho de conclusão de Curso de Especialização em Motricidade Oral da Universidade Luterana do Brasil - ULBRA, realizado no Hospital Luterano - ULBRA - Canoas (RS), Brasil.

Endereço para correspondência: Susana Elena Delgado. R. Pedro Chaves Barcellos, 892/201, Bela Vista, Porto Alegre - RS, CEP 90450-010. E-mail: sudel.ez@terra.com.br

Recebido em: 8/5/2006; Aceito em: 30/10/2006 parenteral é indicada em casos de recém-nascido com muito baixo peso, submetidos à ventilação mecânica, na presença de sepse, de asfixia perinatal, de patologias cirúrgicas e em pós-operatório, ou patologia que impeça alimentação enteral ${ }^{(1)}$.

A gavagem gástrica contínua é utilizada em recém-nascidos $(\mathrm{RN})$ imaturos, principalmente sob ventilação mecânica, pois a oferta de uma quantidade pequena de alimento no trato gastrintestinal, porém contínua, propicia a nutrição trófica da mucosa, impedindo a translocação bacteriana e preparando o intestino para receber dieta láctea adequada, posteriormente ${ }^{(2)}$.

A nutrição enteral é indicada para RNPT que são impedidos de ser amamentados em conseqüência dos déficits maturacionais fisiológicos. Essa imaturidade apresenta como resultado a incoordenação na sucção-respiração-deglutição, o que representa também dificuldade de alimentação por via oral, sendo necessária utilização de alimentação enteral, através de sondas nasogástrica (SNG) ou orogástrica (SOG), pelas quais o alimento é depositado diretamente no tubo digestivo do RN.

Ambos os tipos de sonda apresentam vantagens e desvantagens para os RN. Uma das vantagens da SNG é que esta é mais fácil de fixar e mais duradoura; outra vantagem é 
deixar a cavidade oral livre para receber os estímulos. Por outro lado, a SNG provoca um aumento na resistência das vias aéreas, propiciando ocorrência de apnéias; além disso, quando utilizada por um período mais longo, pode desencadear refluxo gastroesofágico $(\mathrm{RGE})^{(1)}$. A SOG é preferível a SNG, apesar desta ser mais estável em seu posicionamento por permitir que as narinas fiquem livres, auxiliando, desta forma, na respiração do bebê. No entanto, a SOG apresenta a desvantagem de ser um estimulador dos sensores vagais, provocando aumento da freqüência respiratória e cardíaca ${ }^{(3)}$. Seu uso prolongado pode contribuir para alterar as estruturas orais, principalmente, o palato duro e mole e a gengiva superior. Podem ocorrer alterações no que se refere à forma, à mobilidade, à tonicidade e, principalmente, à sensibilidade oral $^{(4)}$.

O fonoaudiólogo é um dos profissionais capacitados para atuar em berçário neonatal com RNPT e a termo, que apresentam dificuldades na alimentação e que necessitam de nutrição parenteral/gavagem e/ou enteral. O objetivo desse profissional é a adequação do sistema estomatognático à estimulação da alimentação oral de forma segura e eficaz, e à promoção do aleitamento materno.

A avaliação clínica do fonoaudiólogo no berçário neonatal tem início no levantamento aprofundado da história do RN, obtida por meio do prontuário, do contato com a equipe e com a família. São levantados os dados relativos à história da gestação e parto, à idade gestacional, ao peso do nascimento, ao Apgar, às intercorrências clínicas no período pósnatal imediato e mediato, à medicação em uso, à necessidade de ventilação mecânica e tempo de permanência no aparelho e, ainda, ao tipo, à forma e ao volume prescrito de alimentação. O manuseio direto do $\mathrm{RN}$ ou lactente realizado pelo fonoaudiólogo deve ocorrer sempre antecedendo o horário de alimentação, pois se espera que neste momento o RN esteja faminto e em estado de alerta ${ }^{(5-6)}$.

Durante o manuseio, é avaliada a sensibilidade táctil extra-oral nas bochechas e nos lábios, a sensibilidade intraoral na papila palatina, e os reflexos orais que irão garantir a alimentação do RN nessa fase inicial do desenvolvimento. Esses são: busca ou procura, reflexo que é eliciado pelo toque nos quatro pontos cardeais dos lábios, cuja principal função consiste em localizar o peito; sucção, desencadeado pelo toque na ponta da língua e papila palatina, cuja função é a retirada do leite; deglutição, desencadeada mediante estímulo do leite na região posterior da língua, véu palatino, faringe e epiglote. São avaliados, ainda, os reflexos de proteção, que são o de mordida, desencadeado mediante o toque na região interna das gengivas, e nauseoso, eliciado pelo estímulo na parte posterior da língua ou faringe ${ }^{(5)}$.

Na avaliação da sucção não nutritiva (SNN) são verificados: a presença ou ausência de sucção, a força, o ritmo, as pausas e a coordenação com a deglutição. A investigação da sucção nutritiva (SN) é realizada quando o RN inicia a alimentação por via oral (VO) e é avaliada a postura, o tempo que permanece sugando, o estado de consciência, além, dos itens avaliados na $\mathrm{SNN}^{(6)}$.

Durante a amamentação do RN, o fonoaudiólogo avalia a pega correta, pois, apesar de a sucção ser um ato reflexo, a extração do leite não o é, e exige do RN aprender a retirar o leite do peito, adaptando suas condições orais anatômicas para a ordenha correta na mama da mãe. Outro ponto importante a ser avaliado se refere ao posicionamento da mãe e do bebê, uma vez que uma posição incorreta dificulta que a boca se encaixe corretamente no aréolo-mamilar, levando, muitas vezes, a traumas mamilares, dor e desconforto para a mãe. $\mathrm{O}$ vínculo mãe-bebê também deve ser observado: a forma como a mãe segura o bebê, os toques físicos e o contato visual durante a mamada ${ }^{(1,5)}$.

Por intermédio das observações de avaliação, o fonoaudiólogo poderá detectar disfunções orais como: incoordenação na respiração, sucção e deglutição; reflexos orais de busca, sucção, deglutição, mordida e náusea, ausentes ou incoordenados; ritmo de sucção-deglutição alterado; hipossensibilidade nos lábios, o que poderá ocasionar vedamento labial inadequado; ou hipersensibilidade, dificultando na aceitação do alimento ${ }^{(5)}$. Essas disfunções orais, mencionadas anteriormente, podem ser causadas por diversos fatores e poderão interferir na alimentação por VO.

Outro fator que poderá gerar disfunção oral e prejudicar a alimentação de forma natural, é o fenômeno denominado "confusão de bicos", que ocorre quando é introduzido precocemente um 'bico artificial', seja de mamadeira ou de chupeta, antes da amamentação no seio ter sido realizada com sucesso, levando o neonato a uma dificuldade de exibir a configuração oral correta, com vedamento e padrão de sucção adequado para extrair o leite do peito ${ }^{(5,7)}$.

A intervenção direta com o RNPT deve ser realizada tão logo sejam detectadas alterações no sistema estomatognático, por meio do treino oral da SNN, que consiste na estimulação do reflexo de sucção, repetidamente, de modo sincrônico com o ritmo do bebê, usando como recurso a introdução do dedo mínimo enluvado ou chupeta adequada na boca do RN. Os exercícios para estimulação oral devem ser sempre realizados antes da alimentação, seja por gavagem, sonda, mamadeira ou seio materno, para que seja aproveitada a prontidão e a fome do bebê $\hat{e}^{(5-6)}$.

A literatura aponta, ainda, como benefícios da estimulação da SNN, um maior ganho de peso do RNPT, uma transição mais rápida da alimentação gástrica para a $\mathrm{VO}$, melhora no controle dos estados de consciência, aceleração da maturação do reflexo de sucção, aumento do trânsito gastrintestinal e, conseqüentemente, alta hospitalar precoce.

Os estudos científicos mostram que vários são os fatores que podem interferir no processo de alimentação do RN, sendo um deles a prematuridade, principalmente, quando este bebê, além de pré-termo, nasce com alguma malformação congênita como a gastrosquise.

Nesta patologia, o RN apresenta um defeito congênito na parede abdominal anterior que permite a herniação das vísceras abdominais, geralmente, à direita do cordão umbilical. As alças intestinais e outros órgãos abdominais podem protruir através desta abertura ${ }^{(8-9)}$. $\mathrm{O}$ acidente ocorre intraútero e as alças ganham a cavidade amniótica ficando em contato direto com o líquido. Não existe membrana recobrindo as vísceras ${ }^{(8)}$.

O prognóstico dos RN com gastrosquise apresentou me- 
lhora dramática na segunda metade do século XX. Até 1960, a gastrosquise era vista como apenas uma curiosidade teratológica, confundida com a onfalocele e o prognóstico era sombrio, com praticamente $100 \%$ de mortalidade. Atualmente, nos países desenvolvidos, a taxa de sobrevivência atinge quase $100 \%$ nos casos não-complicados ${ }^{(8-9)}$. O aprimoramento das técnicas de cirurgia neonatal, a nutrição parenteral total e a terapia intensiva neonatal são os grandes responsáveis pelos melhores resultados ${ }^{(9)}$.

A gastrosquise pode ser diagnosticada por meio da ultrasonografia, a partir da $12^{\mathrm{a}}$ semana de gestação ${ }^{(10)}$. É considerada um evento esporádico com etiologia multifatorial. É mais freqüente em gestantes jovens e sua incidência gira em torno de 1 a 2,11 em 10.000 nascidos $\operatorname{vivos}^{(10)}$, e parece não haver predominância de um dos sexos. A predominância em gestantes jovens pode ser secundária ao estilo de vida, relacionado a uma maior exposição a agentes teratogênicos. $\mathrm{O}$ defeito é provavelmente devido à isquemia, como resultado da disrupção da artéria onfalomesentérica ou da involução anormal da veia umbilical direita ${ }^{(9-10)}$.

A abordagem terapêutica visa evitar a infecção, reintroduzir as alças na cavidade peritoneal e nutrir o RN até que seja normalizado o trânsito intestinal. A cirurgia deve ser realizada logo após o nascimento. Até as alças readquirirem o seu tônus e o trânsito intestinal se refazer, o RN necessita ser mantido em nutrição parenteral periférica, o que poderá ocorrer por um período de 3 a 4 semanas ${ }^{(8)}$. Quando não existem outras malformações associadas, o prognóstico é muito bom, com uma taxa de sobrevida pós-cirúrgica de $43 \%$ a $92,3 \%{ }^{(10)}$

Embora tenha sido feita uma revisão ampla da literatura, não encontramos artigos que descrevam a intervenção fonoaudiológica em bebês com gastrosquise.

Portanto, o objetivo deste estudo foi descrever a intervenção fonoaudiológica para adequação da função alimentar, por meio da avaliação e tratamento dos órgãos do sistema estomatognático e suas funções, a partir do relato de caso de um RNPT com gastrosquise, alimentado por sonda e internado em UTI neonatal.

\section{APRESENTAÇÃO DO CASO}

Este estudo é do tipo observacional, exploratório, de caso, contemporâneo, prospectivo e está vinculado a outro projeto realizado na mesma instituição*, aprovado pelo Comitê de Ética do Grupo de Pesquisa da Universidade Luterana do Brasil - ULBRA, sob n 2004-303H.

As informações do paciente foram obtidas por meio de consulta ao prontuário padronizado do serviço de Neonatologia, de onde foram coletados dados da história gestacional e do parto, condições do bebê ao nascer, peso, data da internação, intercorrências clínicas durante a internação, diagnósticos, uso de sondas para alimentação, condições clínicas gerais atuais e anotadas na ficha de levantamento de dados (Anexo 1). A avaliação fonoaudiológica foi realizada, seguindo o protocolo padronizado do serviço de Neonatologia, no qual foram realizadas observações pré-alimentacão: da postura; do estado de consciência; do tônus da musculatura global; da estabilidade respiratória; dos órgãos do sistema estomatognático (lábios, língua no repouso, língua na sucção e deglutição, bochechas, mandíbula, palato duro) e dos reflexos orais (busca, sucção, deglutição, mordida, nauseoso); da SNN, antes da alimentação e durante a alimentação com sonda (sucções/pausas, ritmo, força, pausas) com introdução do dedo mínimo enluvado dentro da cavidade oral do RN e por intermédio da chupeta convencional; e da SN na mamadeira e seio materno (sucções/pausas, tempo de alimentação, sinais de estresse (Anexo 2).

A observação de assistência à alimentação foi registrada no protocolo da UTI neonatal (Anexo 3). Foram realizadas uma sessão de avaliação e três sessões de intervenção fonoaudiológica, ocorrendo o acompanhamento durante três semanas. A equipe de enfermagem e a mãe foram orientadas a realizar a estimulação oral, nos demais dias da semana, pelo menos três vezes por dia, antes da alimentação. Em uma das sessões foram dadas orientações para a mãe sobre a importância da amamentação e do uso adequado de chupetas ortodônticas para o correto desenvolvimento dos órgãos do sistema estomatognático. Na última sessão, foi realizada a reavaliação.

O compromisso de sigilo para a utilização dos dados do prontuário usado no estudo de caso, obrigatório para pesquisa com seres humanos (Resolução N 196/96), foi assinado pelo pesquisador responsável.

O RNPT do estudo era do sexo masculino, nascido 19/ 03/2005, no hospital do município de Cachoeirinha. Nasceu de cesárea, de mãe primípara, com idade gestacional de 36 semanas, com peso de 2.460 gramas e $45 \mathrm{~cm}$ de comprimento. Apresentou um Apgar 8 no 1' e 9 no 5', sendo transferido para o Hospital Luterano por apresentar gastrosquise e necessitar de cirurgia para correção da malformação. O procedimento cirúrgico ocorreu em 28/03/2005. Após a cirurgia, o RNPT foi atendido na UTI neonatal, no período de 29/03/ 2005 a 22/04/2005, fazendo uso de SNG até 03/04/2005 e mantendo nutrição parenteral até 07/04/2005, quando iniciou VO.

$\mathrm{Na}$ avaliação fonoaudiológica, o RNPT, mantido em berço aquecido, encontrava-se na postura de decúbito dorsal, com estado de consciência alerta, tônus da musculatura global normal e boa estabilidade respiratória. $\mathrm{Na}$ avaliação dos órgãos do sistema estomatognático, foram observados lábios com vedamento, língua no repouso no soalho da boca, língua na sucção e deglutição com canolamento e mobilidade funcional, bochechas simétricas e com coxins, mandíbula retraída, palato duro normal, reflexos orais (busca, sucção, deglutição, mordida, nauseoso) presentes. A SNN, avaliada pela introdução do dedo mínimo enluvado na cavidade oral do $\mathrm{RN}$ e por meio da chupeta convencional, apresentou como resultado um número de sucções/pausas de 8:1, com ritmo presente, com força adequada.

\footnotetext{
* O presente estudo está vinculado ao projeto "Caracterização do desenvolvimento da alimentação de bebês de risco internandos na UTI Neonatal", sob responsabilidade da fonoaudióloga Susana Elena Delgado.
} 
A primeira avaliação da SN na mamadeira, apresentou sucções/pausa de 23:1, pausas longas, demorando um tempo de $10 \mathrm{~min}$, aceitando $5 \mathrm{ml}$ dos $15 \mathrm{ml}$ prescritos. Foi observado sinal de estresse de alteração respiratória e reflexo de náusea anteriorizado e exacerbado, demonstrando hipersensibilidade oral em resposta ao bico convencional da mamadeira.

$\mathrm{Na}$ avaliação da $\mathrm{SN}$ no seio materno, o RN apresentou dificuldade, não conseguindo realizar a pega correta. Foram realizadas manobras de ajuda para tentar facilitar o processo, mas o bebê não conseguiu sugar. Em 15/04/2005, a alimentação passou a ser só por VO de $3 / 3$ horas, aceitando $15 \mathrm{ml}$ dos $30 \mathrm{ml}$ prescritos, apresentando um ritmo de $\mathrm{SN}$ em 10 seg de pausas de 6:1 com força adequada.

A intervenção fonoaudiológica foi realizada sempre antes da alimentação e consistia em estimular a região peri e intra-oral feita com o dedo mínimo enluvado, ou com a chupeta, visando melhora da função, ritmo adequado e amadurecimento do reflexo de sucção e coordenação, com deglutição e respiração, e propiciar a amamentação no seio materno.

As orientações dadas à mãe sobre a amamentação foram no sentido de continuar colocando o bebê no peito para estimular a pega correta, observando a postura dos lábios, a postura corporal e procurando manter contato visual, assim como realizando carícias, propiciando, dessa forma, um bom vínculo mãe-bebê. Além das orientações para incentivar a amamentação, a mãe foi informada sobre a importância do uso da chupeta e bico de mamadeira do tipo ortodôntico por terem conformação mais semelhante com o bico do seio materno.

Em 22/04/2005, o RN recebeu alta hospitalar, mamando no seio materno e aceitando toda a quantidade de alimentação prescrita na mamadeira.

\section{DISCUSSÃO}

Um dos principais objetivos da avaliação e intervenção fonoaudiológica com RNPT, dentro da UTI Neonatal, é determinar de forma segura o momento ideal para a transição alimentar da sonda para a VO. Portanto, é de extrema importância o conhecimento deste profissional dos fatores que podem interferir neste processo ${ }^{(11)}$.

O processo pode não acontecer de forma natural se o RN apresentar alterações como as que foram identificadas nas avaliações realizadas no RNPT do caso apresentado, tais como: hipersensibilidade oral e reflexo nauseoso exacerbado - alteração provocada, provavelmente, pelo uso da sonda, pois segundo estudos relatados na literatura, os lábios e a língua possuem uma grande quantidade de receptores sensoriais que, quando expostos a estímulos sensoriais negativos, resultantes de procedimentos como aspiração, intubação e uso de sondas oro ou nasogástricas, levam à hipersensibilidade oral. Esse fator pode levar à recusa alimentar, retardando o início da alimentação por $\mathrm{VO}^{(5,11)}$.

Além disso, o paciente apresentou, quando da liberação da VO, um grupo de sucções nutritivas na mamadeira de 23:1, resultando em sinal de estresse de alteração respiratória, comprovando, assim, segundo a literatura, que grupos de suc- ções nutritivas acima de oito por grupo podem ser acompanhados de alterações na frequiência respiratória ${ }^{(1)}$. Esta alteração pode influenciar a segurança da alimentação por VO, interferindo na coordenação das funções de deglutição com a respiração ${ }^{(11)}$.

Dificuldade para sugar o peito da mãe, apesar de já demonstrar condições de sucção adequada na mamadeira, também foi observada, possivelmente, comprovando o que os autores referem sobre a dificuldade do neonato em exibir uma configuração oral correta, com vedamento e padrão de sucção necessário para extrair o leite do peito. Entre as causas para isto acontecer, assinaladas na literatura, destaca-se o fato de ter sido apresentado ao RN um bico artificial, antes da amamentação natural ter acontecido com sucesso, fenômeno este denominado "confusão de bicos" ${ }^{(5,7)}$.

Por intermédio da estimulação do sistema estomatognático, com manuseio peri e intra-oral e uso da chupeta, foram realizadas as intervenções fonoaudiológicas com o objetivo de adequar a sensibilidade oral alterada, organizar a coordenação das funções de deglutição com respiração e estimular a pega correta na mama da mãe. Os manejos foram realizados com o RN em estado de alerta de forma organizada e por um período aproximado de cinco a dez minutos, antes da alimentação.

Alguns estudos ${ }^{(1,6,12-13)}$ relataram os benefícios da estimulação oral como facilitadora na transição da alimentação por sonda para a VO. A SNN, quando realizada antes da dieta, leva a um melhor ganho de peso, uma vez que o RN estimulado mama todo o volume prescrito com maior facilidade, ativa o comportamento reflexo de procura, sucção e deglutição, favorecendo a alimentação por mamadeira ou seio materno mais precocemente, facilitando o vínculo mãe-bebê e alta hospitalar precoce ${ }^{(1,11-13)}$. Isto se comprovou pelos resultados obtidos com o RN do estudo, que recebeu alta sem alterações sensório motoras e mamando no seio materno complementado com mamadeira.

A amamentação exerce um papel muito importante no desenvolvimento do bebê. Além de ser a forma mais saudável de alimentação, proporciona um correto desenvolvimento do sistema estomatognático e fortalece os laços afetivos entre a díade mãe-bebê. Já na prematuridade ou na privação da via oral por tempo prolongado, muitas vezes, o aleitamento materno é acompanhado de insegurança, ansiedade e sofrimento $^{(14)}$.

Alguns estudos ${ }^{(14-15)}$ realizados com o objetivo de verificar os sentimentos de mães de prematuros em relação à amamentação, constataram que muitas das nutrizes entrevistadas passaram por um período estressante, onde emergiram conflitos contraditórios entre o discurso técnico e a prática de amamentar esse bebê. A dúvida, o medo da incapacidade de manter a lactação por meio da ordenha, confrontados com as orientações recebidas que enfatizavam a sucção no seio materno, o receio de o bebê não conseguir pegar o peito, o ingurgitamento mamário e a dor que acompanhava a ordenha, eram sentimentos que faziam parte do cotidiano dessas mães, enquanto o bebê ainda não estava mamando no seio.

Sentimentos de angústia e ansiedade podem levar as mães a questionamentos quanto à capacidade de alimentar seus 
bebês adequadamente, situação que pode levar ao desmame precoce $^{(15)}$, se os profissionais que atuam junto às duplas não ficarem atentos aos aspectos psicossociais que envolvem a alimentação $^{(1)}$. Eles devem olhar cada mãe não como uma nutriz fracassada, e sim como uma mãe que está envolvida com sentimentos que geram emoção e contradição como resultado da situação de ter um bebê prematuro e das dificuldades de ter que amamentá-lo ${ }^{(14)}$.

É necessário que os profissionais da equipe de saúde ajam de forma a desenvolver confiança e tranqüilidade, mostrando as mães destes bebês que a amamentação consiste em um processo de aprendizagem que ocorre de forma gradual, no qual alguns comportamentos dos prematuros são esperados ${ }^{(15)}$.

A equipe que atende aos bebês precisa estar consciente da importância do afeto e respeito que estas mães e seus filhos necessitam neste momento crítico de suas vidas. Ela deve estar preparada para realizar a escuta daquilo que a mãe está tentando mostrar, desempenhando, desta forma, a função de mediadora na relação mãe-bebê, facilitando a construção do primeiro vínculo do $\mathrm{RN}$, crucial para o desenvolvimento de sua saúde física e mental ${ }^{(15)}$.

Levando em consideração todas as questões que envolvem a amamentação, as orientações dadas à mãe pelo fonoaudiólogo, foram realizadas com o objetivo de esclarecer dúvidas, desenvolver confiança e tranqüilidade. Foi facilitada a postura corporal, evitando desconforto para a mãe e esforço excessivo do bebê, uma vez que a posição inadequada pode tornar a mamada ineficiente, gerando conflitos e frustrações ${ }^{(5)}$. A mãe foi auxiliada para o bebê realizar a pega correta, assim como, informada sobre a importância do uso de chupetas e bicos de mamadeiras ortodônticos para o desenvolvimento adequado dos órgãos do sistema estomatognático, por se assemelharem à conformação do bico do seio, evitando, desta forma, o desmame precoce.

O fonoaudiólogo, como membro da equipe de saúde, ori- enta as mães sobre como devem amamentar corretamente, dando, desta maneira, o suporte necessário para que elas se sintam seguras e acolham seus bebês. Com sua atuação, o fonoaudiólogo auxilia no restabelecimento da unidade da díade por meio da amamentação e favorece o desabrochar da mãe intuitiva e empática com seu bebê(15).

\section{COMENTÁRIOS FINAIS}

Por intermédio da avaliação fonoaudiológica foi possível detectar as alterações que poderiam levar ao fracasso da alimentação por VO. A hipersensibilidade oral do $\mathrm{RN}$, manifestada pelo reflexo nauseoso anteriorizado e exacerbado, e o ritmo de sucções/pausa demonstrado pelo sinal de estresse de alteração respiratória, sugerem estar relacionadas, de acordo com a literatura consultada, ao uso prolongado da sonda de alimentação. A dificuldade do bebê em sugar o peito, também, só foi possível de ser detectada a partir das observações realizadas pelo fonoaudiólogo na assistência à alimentação.

A intervenção fonoaudiológica realizada pela estimulação dos órgãos do sistema estomatognático e da SNN, as orientações para a equipe de enfermagem, assim como o auxílio dado a mãe, facilitando a pega correta no bico do seio, além das informações sobre a importância da amamentação para o desenvolvimento global do bebê, comprovaram a importância da atuação do fonoaudiólogo como membro da equipe dentro da UTI neonatal, uma vez que o RNPT do estudo de caso teve alta sem alterações no sistema estomatognático, mamando no seio materno com complementação de mamadeira.

Embora o resultado da intervenção tenha sido positivo, é importante ressaltar que idealmente o acompanhamento diário do paciente poderia ter acelerado o estabelecimento da alimentação adequada. Porém, esta não é uma realidade no Serviço, no qual foi realizado o estudo, podendo ser considerado um fator de limitação.

\begin{abstract}
The aim of this study was to describe the speech-language therapy regarding the adequation of the feeding function by assessing and treating the stomatognathic system and its functions. The study was carried out based on a case report of a preterm newborn infant with gastroschisis, who was tube fed while assisted in the Neonatology division of Lutheran Hospital, from 3/29/2005 to 4/ 22/2005. The speech-language pathology assessment was carried out according to a standardized protocol used at the Neonatology service, and showed the following results: the stomatognathic system structures, regarding posture, conformation and mobility, were normal; oral reflexes were present; strength and rhythm were suitable during non-nutritional sucking; the oral sensitiveness was impaired, with an anterior and overactive gag reflex; there was a sign of stress through breathing alteration during nutritional sucking with the bottle, and difficulties in sucking during breastfeeding. Three weekly sessions of speech-language therapy were carried out, and the nursing staff received orientations to continue the oral stimulation during the other days. In one of the sessions the mother received orientations about the benefits of breastfeeding and the importance of the right use of pacifiers and orthodontic bottle teats in order to promote an adequate development of the oral functions. The newborn was discharged with no oral alterations; he was being breastfed and had bottle-feeding as complement, which suggests the effectiveness of speech-language pathology intervention to the adequation of feeding functions.
\end{abstract}

KEYWORDS: Infant, premature; Gastroschisis; Breast feeding; Feeding behavior; Stomatognathic system 


\section{REFERÊNCIAS}

1. Hernandez AM. Atuação fonoaudiológica com recém-nascidos e lactentes disfágicos. In: Hernandez AM, Marchesan IQ. Atuação fonoaudiológica no ambiente hospitalar. Rio de Janeiro: Revinter; c2001. p.1-37.

2. Falcão MC. Terapia nutricional do recém-nascido. In: Hernandez AM, organizadora . Conhecimentos essenciais para atender bem o neonato. São José dos Campos: Pulso Editorial; c2003. p.35-46.

3. Tirado AR, Denzin P, Basseto MCA. Sucção não nutritiva e alimentação do recém-nascido pré-termo. In: Basseto MCA, Brock R, Wajnztejn R. Neonatologia: um convite à atuação fonoaudiológica. São Paulo: Lovise; 1998. p.282-93.

4. Migliónico AM. Estúdio exploratório sobre alimentación en bebés prematuros [tese]. Rosário: Universidad Nacional de Rosário. Facultad de Ciencias Médicas. Escuela de Fonoaudiologia; 1999.

5. Sanches MTC. Manejo clínico das disfunções orais na amamentação. J Pediatr (Rio de J). 2004;80(5 Supl):S155-S162.

6. Andrade ISN, Guedes ZCF. Sucção do recém-nascido prematuro: comparação do método mãe-canguru com os cuidados tradicionais. Rev Bras Saúde Matern Infant. 2005;5(1):61-9.

7. Neifert M, Lawrence R, Seacat J. Nipple confusion: toward a formal definition. J Pediatr. 1995;126(6):S125-9.

8. Maranhão R. Recém-nascido com patologias cirúrgicas. In: Basseto MCA, Brock R, Wajnztejn R. Neonatologia: um convite à atuação fonoaudiológica. São Paulo: Lovise; 1998. p.213-33.
9. Voz EF, Resende MAC, Panha A, Garrido E, Miranda LCM. Manuseio anestésico de paciente com gastrosquise. São Paulo Med J. 2005;123(Suppl Esp):45.

10. Patroni L, Brizot ML, Mustafá SA, Carvalho MHB, Silva MM, Miyadahira S, Zugaib M. Gastrosquise: avaliação pré-natal dos fatores prognósticos para sobrevida pós-natal. Rev Bras Ginecol Obstet. 2000;22(7):421-8.

11. Bühler KEB, Limongi SCO. Fatores associados à transição da alimentação via oral em recém-nascidos pré-termo. Pró-Fono. 2004;16(3):301-10.

12. Fucile $\mathrm{S}$, Gisel E, Lau C. Oral stimulation accelerates the transition from tube to oral feeding in preterm infants. J Pediatr. 2002;141(2):230-6. Erratum in: J Pediatr. 2002;141(5):743.

13. Simão KC, Mallet NR, Sant'Anna GM, Ramos JR, Meio MD. Estimulação sensório-motora oral em neonatos prematuros com peso de nascimento inferior a 1.501 g. Fono Atual. 2001;4(15):35-8.

14. Javorski M, Caetano LC, Vasconcelos MGL, Leite AM, Scochi CGS. As representações sociais do aleitamento materno para mães de prematuros em unidade de cuidado canguru. Rev Latinoam Enfermagem. 2004;12(6):890-8.

15. Delgado SE, Halpern R. Aleitamento materno de bebês pré-termo com menos de 1.500 gramas: sentimentos e percepções maternos. Arq Méd Univ Luterana do Brasil. 2004;7(2):5-28.

Anexo 1. Ficha de levantamento de dados

FICHA DE LEVANTAMENTO DE DADOS

\section{Identificação do RN}

Nome da mãe:

Nome do RN:

DN: sexo: Peso: Data atual:

\section{Manifestações do RN}

Apgar: $1^{\prime}$ 5 “

Peso ao nascer:

Comprimento: Idade gestacional:

Manobras de reanimação:

Uso de sonda:

Alimentação atual:

3. Resumo do caso:

\section{Diagnóstico do Pediatra:}

\section{Outras informações:}


Anexo 2. Avaliação fonoaudiológica

\section{AVALIAÇÃO FONOAUDIOLÓGICA}

Nome da mãe:

Identificação do paciente:

$\mathrm{RN}$ :

Data:

1. Observação pré-alimentação

Postura:

Estado de consciência:

Tônus da musculatura global:

Estabilidade respiratória:

2. Estruturas do SISTEMA ESTOMATOGNÁTICO:

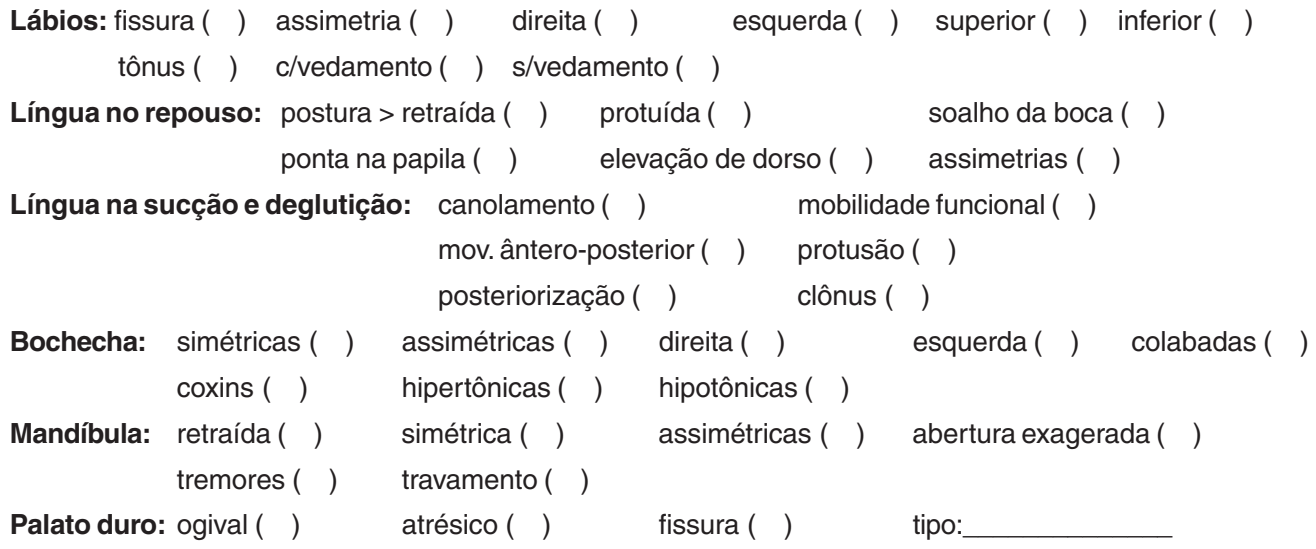

3. Reflexos orais:

Busca:

Sucção:

Deglutição:

Mordida:

Reflexo nauseoso:

\section{Sucção não-nutritiva:}

Antes da alimentação:

Sucções x pausas:

Ritmo: presente ( ) desorganizado ( ) inconsistente ( )

Força: adequada( ) moderada( ) débil( ) exagerada ( )

Pausas: rítmicas ( ) longas ( ) curtas ( )

Durante a alimentação com sonda:

Sucções x pausas:

Ritmo: presente ( ) desorganizado ( ) inconsistente ( )

Força: adequada ( ) moderada ( ) débil ( ) exagerada ( )

Pausas: rítmicas（ ) longas（） curtas（ )

\section{Sucção Nutritiva:}

Sucções $x$ pausas:

Pausas: ausentes ( ) longas（） curtas（） adequadas（）

Tempo de alimentação:

Sinais de estresse: escape de líquido ( ) alteração respiratória ( ) cianose ( )

Variação de tônus global（） sonolência（） palidez（） 
Anexo 3. Ficha de observação da assistência à alimentação

FICHA DE OBSERVAÇÃO DA ASSISTÊNCIA À ALIMENTAÇÃO

RN : Localização na unidade:

Examinador:

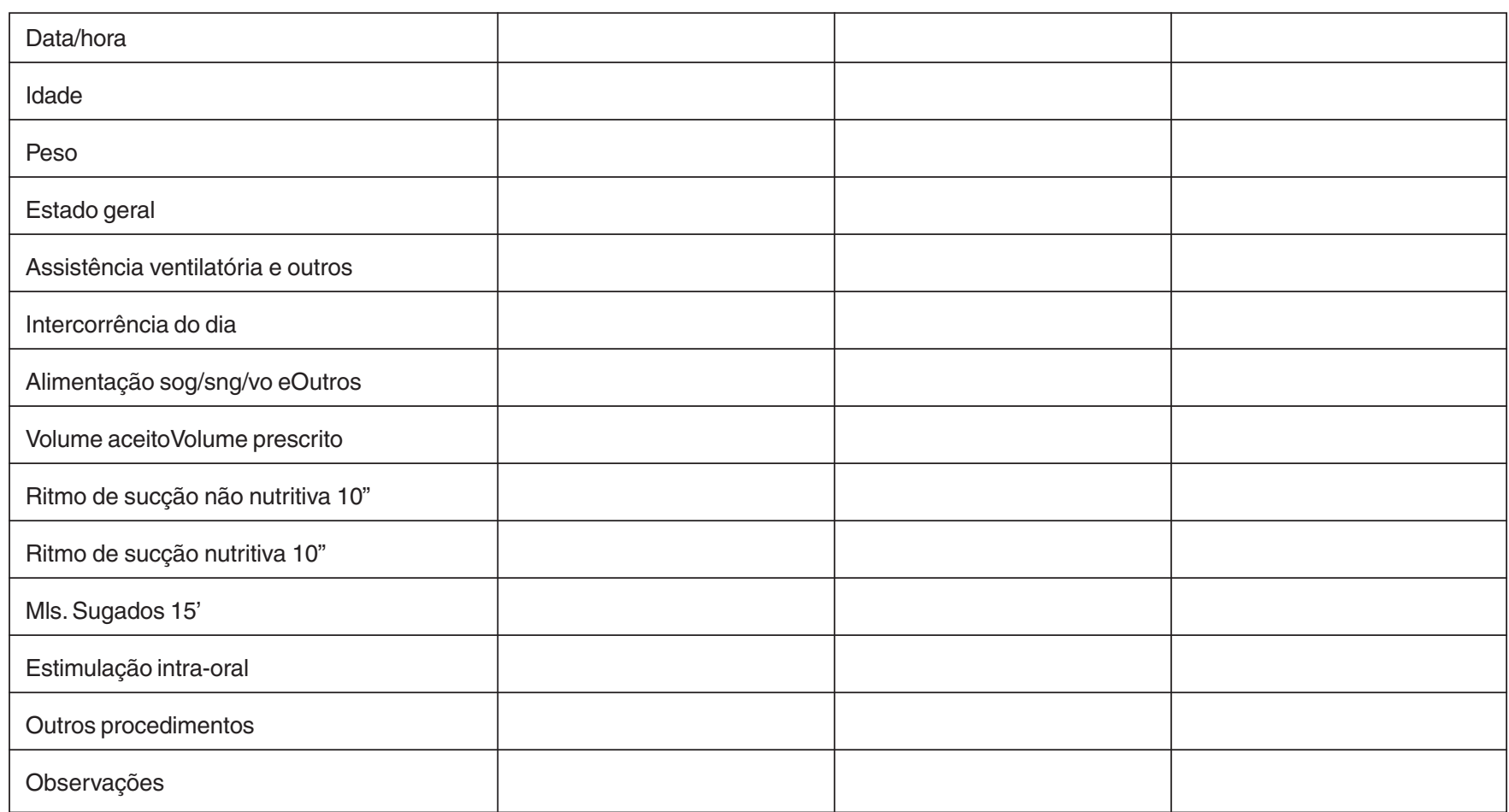

